\title{
The fate of manuscripts rejected from Kidney Research and Clinical Practice
}

\author{
Sungjin Chung ${ }^{1,2(\mathbb{D})}$, Jeonghwan Lee ${ }^{1,3(\mathbb{D})}$, Tae-Hyun Yoo ${ }^{1,4(\mathbb{D})}$, Gheun-Ho Kim ${ }^{1,5(\mathbb{D})}$ \\ 'Editorial Board, Kidney Research and Clinical Practice, Official Journal of the Korean Society of Nephrology, Seoul, Republic of Korea \\ ${ }^{2}$ Department of Internal Medicine, College of Medicine, The Catholic University of Korea, Seoul, Republic of Korea \\ ${ }^{3}$ Department of Internal Medicine, SMG-SNU Boramae Medical Center, Seoul, Republic of Korea \\ ${ }^{4}$ Department of Internal Medicine, Yonsei University College of Medicine, Seoul, Republic of Korea \\ ${ }^{5}$ Department of Internal Medicine, Hanyang University College of Medicine, Seoul, Republic of Korea
}

All researchers aim to publish their works in highimpact journals because success in research is usually judged by publications within the scientific community [1]. On the other hand, every journal wants to recruit high-quality and decent papers that will be frequently cited in other journals $[2,3]$. This is a way for a journal to secure its reputation despite general debate and criticism on the reliability of the impact factor as a measure of a journal [2,4]. In 2011, the Korean Society of Nephrology, led by Dr. Yoon Sik Chang at the time, planned to enhance its own official journal by extending the scope of readership beyond its regional boundaries to the globe. Commencing with volume 31 in 2012, The Korean Journal of Nephrology changed its name to Kidney Research and Clinical Practice (KRCP) and became an international, peer-reviewed journal published in English, allowing scientists worldwide to submit their works to the journal.

KRCP editors have made efforts to increase the citations of papers recently published in KRCP and enhance our reputation. To attain this end, high standards for

Received April 8, 2020; Revised April 20, 2020;

Accepted April 23, 2020

Correspondence: Gheun-Ho Kim

Department of Internal Medicine, Hanyang University College of Medicine, 222-1 Wangsimni-ro, Seongdong-gu, Seoul 04763, Republic of Korea. E-mail: kimgh@hanyang.ac.kr

Copyright (c) 2020 by The Korean Society of Nephrology

(a) This is an open-access article distributed under the terms of the Creative Commons Attribution Non-Commercial License (http://creativecommons. org/licenses/by-nc-nd/4.0/), which permits unrestricted non-commercial use, distribution, and reproduction in any medium, provided the original work is properly cited. publication in KRCP have been applied to all submitted manuscripts. Like other journals, some papers have been immediately rejected by deputy editors at our editorial office (desk rejection). This rapid decision is efficient for both authors and reviewers. Although our interesting cases have often been cited by other scientists, we decided not to consider the manuscript category of case reports. Submissions from international researchers have gradually increased in past years, but we have maintained quarterly publication of high-quality articles. Consequently, our current rejection rate is approximately $65 \%$, which is higher than in previous years.

We followed all papers submitted to KRCP from January 2015 to December 2019. Because of our recent editorial policy, the numbers of rejected manuscripts increased (Table 1). However, such a strict selection policy may have been disheartening for authors, lacking specific criticism on the rejected manuscripts and possibly overlooking potentially important papers [5]. Setting aside the evaluation results, some works charting the efforts of individual researchers would remain unpublished to their disappointment. Contrary to these concerns, our search through PubMed, KoreaMed and Google Scholar found that about $69 \%$ of articles rejected from KRCP from 2015 to 2018 were subsequently published in other international or domestic journals or finally in KRCP after resubmission (Fig. 1). Interestingly, quite a few papers accepted elsewhere were published in journals indexed in the Science Citation Index or Science Citation Index Expanded, operated by Clarivate Analytics. We believe that the comments from our reviewers were effective in helping the authors improve their manuscripts to sub- 
Table 1. The rejection numbers of manuscripts submitted to KRCP from January 2015 to December 2019

\begin{tabular}{cccc}
\hline Year & $\begin{array}{c}\text { Desk rejection } \\
\text { by internal reviewers }\end{array}$ & $\begin{array}{c}\text { Rejection after } \\
\text { external peer review }\end{array}$ & $\begin{array}{c}\text { Total } \\
\text { rejection }\end{array}$ \\
\hline 2019 & 27 & 43 & 70 \\
2018 & 32 & 41 & 73 \\
2017 & 16 & 14 & 30 \\
2016 & 7 & 21 & 28 \\
2015 & 9 & 33 & 42 \\
\hline
\end{tabular}

Data are presented as the number.

KRCP, Kidney Research and Clinical Practice.

sequently be accepted by other journals, including ones indexed by a major abstracting and indexing service.

Rejection from a journal does not necessarily mean that the work is of poor quality. Instead, it may be related to the paper's scope, style or theme differing from the requirements of the journal [2]. Furthermore, authors can turn failure into opportunity by publishing their valuable discoveries in other peer-reviewed journals. The editors and editorial board of KRCP are deeply indebted to all of their authors for submitting their 'tour de force'. It goes without saying that the reviewers and readers of KRCP are also important contributors, judging the submitted manuscripts and spreading papers published in the journal.

\section{Conflicts of interest}

All authors are members of the Korean Society of Nephrology, serving as editors of its official journal, Kidney Research and Clinical Practice. No other competing interests are declared.

\section{Authors' contributions}

Sungjin Chung, Jeonghwan Lee, Tae-Hyun Yoo, and Gheun-Ho Kim designed the study. Sungjin Chung par-

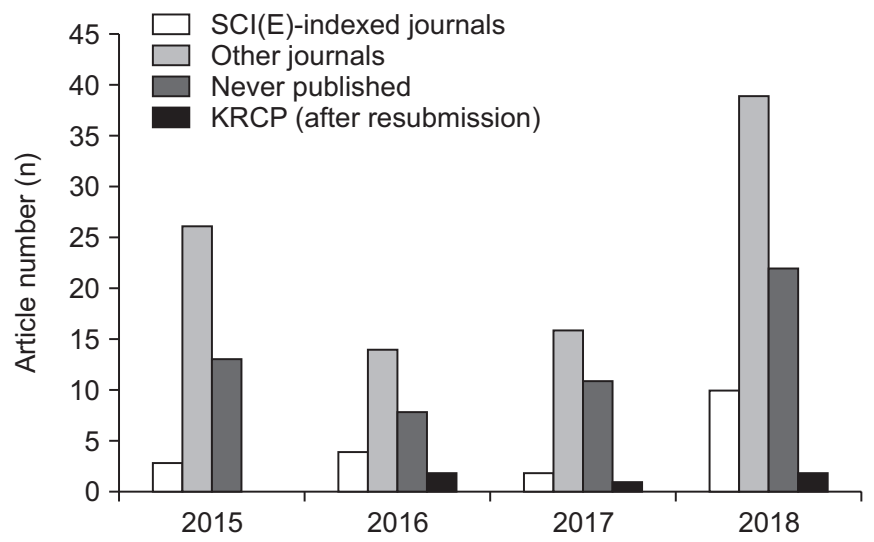

Figure 1. Destinations of articles rejected by KRCP from January 2015 to December 2018.

KRCP, Kidney Research and Clinical Practice; SCI(E), Science Citation Index or Science Citation Index Expanded.

ticipated in the data collection and analyzed the data. Jeonghwan Lee and Tae-Hyun Yoo provided intellectual content on the critical importance of the work. Sungjin Chung and Gheun-Ho Kim wrote the manuscript. All authors read and approved the final manuscript.

\section{References}

[1] Citerio G, Deutsch E, Sala E, et al. Fate of manuscripts rejected by Intensive Care Medicine from 2013 to 2016: a follow-up analysis. Intensive Care Med 2018;44:2300-2301.

[2] Docherty AB, Klein AA. The fate of manuscripts rejected from Anaesthesia. Anaesthesia 2017;72:427-430.

[3] Hesterman CM, Szperka CL, Turner DP. Reasons for manuscript rejection after peer review from the journal Headache. Headache 2018;58:1511-1518.

[4] Moustafa K. The disaster of the impact factor. Sci Eng Ethics 2015;21:139-142.

[5] Zoccali C, Amodeo D, Argiles A, et al. The fate of triaged and rejected manuscripts. Nephrol Dial Transplant 2015; 30:1947-1950. 